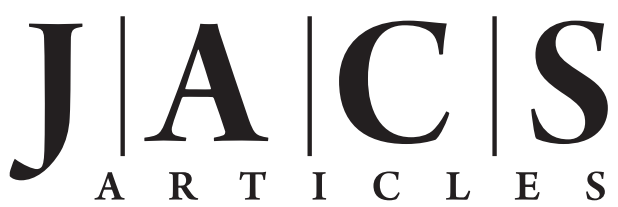

Published on Web 08/04/2009

\title{
Structural Flexibility Enhances the Reactivity of the Bioremediator Glycerophosphodiesterase by Fine-Tuning Its Mechanism of Hydrolysis
}

\author{
Kieran S. Hadler, ${ }^{\dagger}$ Nataša Mitić, ${ }^{\dagger}$ Fernanda Ely, ${ }^{\dagger}$ Graeme R. Hanson, ${ }^{\ddagger}$ \\ Lawrence R Gahan, ${ }^{\dagger}$ James A. Larrabee, ${ }^{\S}$ David L. Ollis," and Gerhard Schenk*,† \\ School of Chemistry and Molecular Biosciences, The University of Queensland, St. Lucia, \\ Queensland, 4072, Australia, Centre for Magnetic Resonance, The University of Queensland, St. \\ Lucia, Queensland, 4072, Australia, Department of Chemistry and Biochemistry, Middlebury \\ College, Middlebury, Vermont 05753, and Research School of Chemistry, Australian National \\ University, Canberra, ACT, 0200, Australia
}

Received May 1, 2009; E-mail: schenk@uq.edu.au

\begin{abstract}
The glycerophosphodiesterase from Enterobacter aerogenes (GpdQ) belongs to the family of binuclear metallohydrolases and has attracted recent attention due to its potential in bioremediation. Formation of a catalytically competent binuclear center is promoted by the substrate (Hadler et al. J. Am. Chem. Soc. 2008, 130, 14129). Using the paramagnetic properties of $\mathrm{Mn}(\mathrm{II})$, we estimated the $K_{\mathrm{d}}$ values for the metal ions in the $\alpha$ and $\beta$ sites to be 29 and $344 \mu \mathrm{M}$, respectively, in the absence of a substrate analogue. In its presence, the affinity of the $\beta$ site increases substantially $\left(K_{d}=56 \mu \mathrm{M}\right)$, while that of the $\alpha$ site is not greatly affected $\left(K_{d}=17 \mu \mathrm{M}\right)$. Stopped-flow fluorescence measurements identified three distinct phases in the catalytic turnover, associated with the initial binding of substrate to the active site $\left(k_{\mathrm{obs} 1}\right)$, the assembly of a catalytically active binuclear center $\left(k_{\mathrm{obs} 2}\right)$, and subsequent slower structural rearrangements to optimize catalysis $\left(k_{\mathrm{obs} 3}\right)$. These three phases depend on the concentration of substrate ([S]), with $k_{\mathrm{obs} 1}$ and $k_{\text {obs2 } 2}$ reaching maximum values at high [S] (354 and $38 \mathrm{~s}^{-1}$, respectively), whereas $k_{\text {obs } 3}$ is reduced as [S] is increased. The $k_{\text {cat }}$ for the hydrolysis of the substrate bis (para-nitrophenyl) phosphate $\left(\sim 1 \mathrm{~s}^{-1}\right)$ gradually increases from the moment of initiating the reaction, reaching a maximum when the structural change associated with $k_{\mathrm{obs} 3}$ is complete. This structural change is mediated via an extensive hydrogen-bond network that connects the coordination sphere with the substrate binding pocket, as demonstrated by mutation of two residues in this network (His81 and His217). The identities of both the substrate and the metal ion also affect interactions within this $\mathrm{H}$-bond network, thus leading to some mechanistic variations. Overall, the mechanism employed by GpdQ is a paradigm of a substrate- and metal-ion-induced fit to optimize catalysis.
\end{abstract}

\section{Introduction}

Glycerophosphodiesterase from Enterobacter aerogenes $(\mathrm{GpdQ})$ is a binuclear metallohydrolase ${ }^{1-5}$ that displays remarkable activity toward all classes of phosphate ester substrates. ${ }^{6,7}$ Notably, GpdQ is capable of degrading EA 2192, a toxic product formed by the hydrolysis of VX (a powerful nerve agent), ${ }^{6}$ as well as a number of organophosphate pesticides (e.g., paraoxon

'School of Chemistry and Molecular Biosciences, The University of Queensland.

Centre for Magnetic Resonance, The University of Queensland.

$\S$ Middlebury College.

" Australian National University.

(1) Cleland, W. W.; Hengge, A. C. Chem. Rev. 2006, 106, 3252-3278.

(2) Lowther, W. T.; Matthews, B. W. Biochim. Biophys. Acta 2000, 1477 , $157-167$

(3) Mitić, N.; Smith, S. J.; Neves, A.; Guddat, L. W.; Gahan, L. R.; Schenk, G. Chem. Rev. 2006, 106, 3338-3363.

(4) Wilcox, D. E. Chem. Rev. 1996, 96, 2435-2458.

(5) Crowder, M. W.; Spencer, J.; Vila, A. J. Acc. Chem. Res. 2006, 39, 721-728.

(6) Ghanem, E.; Li, Y.; Xu, C.; Raushel, F. M. Biochemistry 2007, 46, 9032-9040.

(7) McLoughlin, S. Y.; Jackson, C.; Liu, J.-W.; Ollis, D. L. Appl. Environ. Microbiol. 2004, 70, 404-412. and demeton). ${ }^{7}$ For this reason, GpdQ is of great interest for its potential application as a versatile enzymatic bioremediator. ${ }^{6,8,9}$

Crystal structures for various derivatives and complexes of GpdQ have been reported. ${ }^{10-12}$ Structural comparison to other enzymes indicates that GpdQ belongs to the group of $\alpha / \beta$ sandwich metallophosphoesterases, which also includes purple acid phosphatases (PAPs), the $3^{\prime}-5^{\prime}$ cyclic nucleotide diesterase Rv0805 from Mycobacterium tuberculosis, and Mre11 nuclease. ${ }^{13-23}$ The active site (Figure 1) contains two metal-ion binding sites. The metal

(8) Ghanem, E.; Raushel, F. M. Toxicol. Appl. Pharmacol. 2005, 207, S459-S470.

(9) Ely, F.; Foo, J. L.; Jackson, C. J.; Gahan, L. R.; Ollis, D.; Schenk, G. Curr. Top. Biochem. Res. 2007, 9, 63-78.

(10) Hadler, K. S.; Tanifum, E. A.; Yip, S. H.-C.; Mitić, N.; Guddat, L. W.; Jackson, C. J.; Gahan, L. R.; Nguyen, K.; Carr, P. D.; Ollis, D. L.; Hengge, A. C.; Larrabee, J. A.; Schenk, G. J. Am. Chem. Soc. 2008, 130, 14129-14138

(11) Jackson, C. J.; Carr, P. D.; Liu, J.-W.; Watt, S. J.; Beck, J. L.; Ollis, D. L. J. Mol. Biol. 2007, 367, 1047-1062.

(12) Jackson, C. J.; Hadler, K. S.; Carr, P. D.; Oakley, A. J.; Yip, S.; Schenk, G.; Ollis, D. L. Acta Crystallogr. 2008, F62, 681-685.

(13) Guddat, L. W.; McAlpine, A. S.; Hume, D.; Hamilton, S.; de Jersey, J.; Martin, J. L. Structure 1999, 7, 757-767.

(14) Klabunde, T.; Sträter, N.; Fröhlich, R.; Witzel, H.; Krebs, B. J. Mol. Biol. 1996, 259, 737-748. 


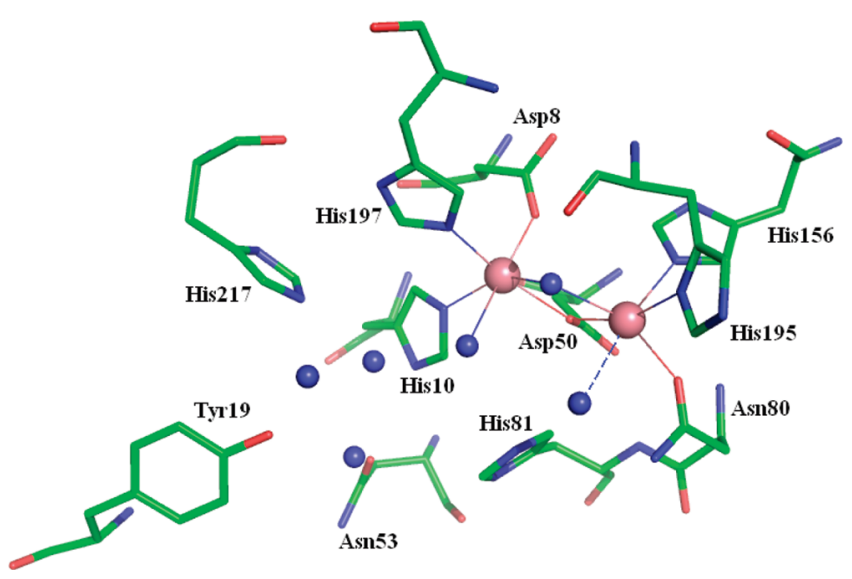

Figure 1. Schematic representation of the active site of GpdQ reconstituted with $\mathrm{Co}(\mathrm{II}) .{ }^{10}$ The metal ion in the $\alpha$ site (left) is six-coordinate, whereas the one in the $\beta$ site (right) is predominantly five-coordinate. However, a terminal water ligand (as indicated by the dashed line) is visible in two out of six subunits in the crystal structure. ${ }^{10}$ This ligand is within hydrogenbonding distance of the amide group of Asn80, the metal-ion-bridging hydroxide, and the water coordinated to the metal ion in the $\alpha$ site.

ion in the $\alpha$ site is coordinated by four amino acid residues, a terminal water ligand, and a hydr(oxide) molecule that bridges the two metal ions. In the $\beta$ site, the metal ion may also be coordinated by four amino acid residues but, based on spectroscopic and kinetic data, is predicted to be less tightly bound (Figure 1). ${ }^{10}$ In addition, a water molecule coordinated to the $\beta$ metal ion is observed in 2 out of 6 subunits in the crystal structure (Figure 1). The physiologically relevant metal-ion composition is unclear; however, the recombinantly expressed, purified enzyme appears to contain at least one $\mathrm{Fe}$ (II) metal ion (in the $\alpha$ site). ${ }^{12}$ Metal-ion replacement studies indicate that GpdQ can operate using a range of divalent transition metal ions, including $\mathrm{Zn}(\mathrm{II}), \mathrm{Cd}(\mathrm{II})$, and $\mathrm{Co}(\mathrm{II}) .^{10-12,24,25}$

Through a combination of solid state (X-ray crystallography) and frozen solution (magnetic circular dichroism (MCD)) studies, possible snapshots of the catalytic mechanism were obtained that enabled us to propose a reaction mechanism for the hydrolysis of phosphate esters by GpdQ. ${ }^{10,11,25}$ It has been postulated that a catalytically competent binuclear metal center is assembled only in the presence of substrate or substrate analogues and that a ligand to the metal ion in the $\beta$ site, Asn80 (Figure 1), may play an important role in regulating enzymatic

(15) Lindqvist, Y.; Johansson, E.; Kaija, H.; Vihko, P.; Schneider, G. J. Mol. Biol. 1999, 291, 135-147.

(16) Schenk, G.; Gahan, L. R.; Carrington, L. E.; Mitić, N.; Valizadeh, M.; Hamilton, S. E.; de Jersey, J.; Guddat, L. W. Proc. Natl. Acad. Sci. U.S.A. 2005, 102, 273-278.

(17) Sträter, N.; Beate, J.; Scholte, M.; Krebs, B.; Duff, A. P.; Langley, D. B.; Han, R.; Averill, B. A.; Freeman, H. C.; Guss, J. M. J. Mol. Biol. 2005, 351, 233-246.

(18) Schenk, G.; Elliott, T. W.; Leung, E.; Carrington, L. E.; Mitić, N.; Gahan, L. R.; Guddat, L. W. BMC Struct. Biol. 2008, 8, 6.

(19) Höpfner, K. P.; Karcher, A.; Craig, L.; Woo, T. T.; Carney, J. P.; Tainer, J. A. Cell 2001, 105, 473-485.

(20) Hadler, K. S.; Huber, T.; Cassady, A. I.; Weber, J.; Robinson, J.; Burrows, A.; Kelly, G.; Guddat, L. W.; Hume, D. A.; Schenk, G.; Flanagan, J. U. BMC Res. Not. 2008, 1, 78.

(21) Shenoy, A. R.; Capuder, M.; Draskovic, P.; Lamba, D.; Visweswariah, S. S.; Podobnik, M. J. Mol. Biol. 2007, 365, 211-225.

(22) Shenoy, A. R.; Sreenath, N.; Podobnik, M.; Kovacevic, M.; Visweswariah, S. S. Biochemistry 2005, 44, 15695-15704.

(23) Keppetipola, N.; Shuman, S. J. Biol. Chem. 2008, 283, 30942-30949.

(24) Gerlt, J. A.; Whitman, G. J. R. J. Biol. Chem. 1975, 250, 5053-5058.

(25) Mirams, R. E.; Smith, S. J.; Hadler, K. S.; Ollis, D. L.; Schenk, G.; Gahan, L. R. J. Biol. Inorg. Chem. 2008, 13, 1065-1072. activity. Furthermore, a histidine residue (His81 or His217), located in the second coordination sphere, was associated with a catalytically relevant $\mathrm{p} K_{\mathrm{a}}$ value $(\sim 7.0)$ and was predicted, based on crystallographic information, to play a role in orientating the substrate and/or protonating the leaving group at low $\mathrm{pH} .{ }^{10}$

The conundrum and challenge of mechanistic studies is the continuous reconciliation between existing catalytic models and new experimental data, leading to gradual improvements in the understanding of the molecular details of a chemical reaction. Numerous examples illustrate this quest, and the enzyme GpdQ is a recent and versatile paradigm whose mode of action may involve an intricate regulatory mechanism. Its efficient use in bioremediation will be greatly assisted by detailed knowledge of its mechanism of action, i.e., the various steps of a catalytic turnover.

Toward this aim, we used stopped-flow fluorescence and absorbance measurements to monitor structural changes that take place when substrate is added to the enzyme and correlated these changes to catalytic properties. Furthermore, we used the paramagnetic properties of $\mathrm{Mn}$ (II) to demonstrate the extent to which a substrate analogue (phosphate) affects metal ions' binding affinities to the active site of GpdQ and determined the dissociation constants of the $\alpha$ and $\beta$ metal ion in the absence or presence of phosphate. In addition, the role of a hydrogenbond network that connects the metal ions with the substrate binding pocket was investigated by (i) site-directed mutagenesis, whereby His81 and His217 (see above) were replaced by alanines, and (ii) metal-ion substitution studies. The combined data demonstrate the mechanistic flexibility of this highly promiscuous enzyme and may provide the basis for using its catalytic potential for bioremedial applications. Considering structural similarities observed in the active sites of GpdQ and other enzymes of the family of bimetallic metallohydrolases (e.g., methionine aminopeptidase $\mathrm{e}^{2,26}$ or various metallo- $\beta$ lactamases ${ }^{5}$ ), it is possible that the mechanistic scheme described here applies in a more general sense to other enzymes within this family. Specifically, it may help to resolve some of the controversies about the metal-ion content and the role(s) of the metal ions in catalysis.

\section{Materials and Methods}

Materials. All chemicals were purchased from Sigma-Aldrich, unless stated otherwise. Bis(para-nitrophenyl) phosphate ( $p p N P P$ ) was purchased in the sodium salt form because of its greater solubility in water. Ethyl para-nitrophenyl phosphate (EtpNPP) was synthesized by known methods. ${ }^{27}$ Chemical structures of the substrates used in this study are shown in Figure S1.

Expression, Purification, and Mutagenesis of GpdQ. GpdQ (wild-type and mutants) were expressed and purified as described previously. ${ }^{7}$ Residues His 81 and His 217 were replaced by alanine using the Stratagene QuikChange kit.

Preparation of Metal Ion Derivatives of GpdQ. The Co(II)and $\mathrm{Cd}(\mathrm{II})$-derivatives of $\mathrm{GpdQ}$ were prepared as previously described. ${ }^{10,25}$ The $\mathrm{Mn}$ (II) form was prepared by adding a $99.9 \%$ pure metal chloride solution to the apoenzyme (prepared as described elsewhere ${ }^{10}$ ).

Characterization of the Metal Binding Affinity of Mn(II)-GpdQ. The binding of Mn(II) to apo-GpdQ was monitored by electron paramagnetic resonance (EPR) at room temperature.

(26) Lowther, W. T.; Matthews, B. W. Chem. Rev. 2002, 102, 4581-4607. (27) Hendry, P.; Sargeson, A. M. J. Am. Chem. Soc. 1989, 111, 25212527. 


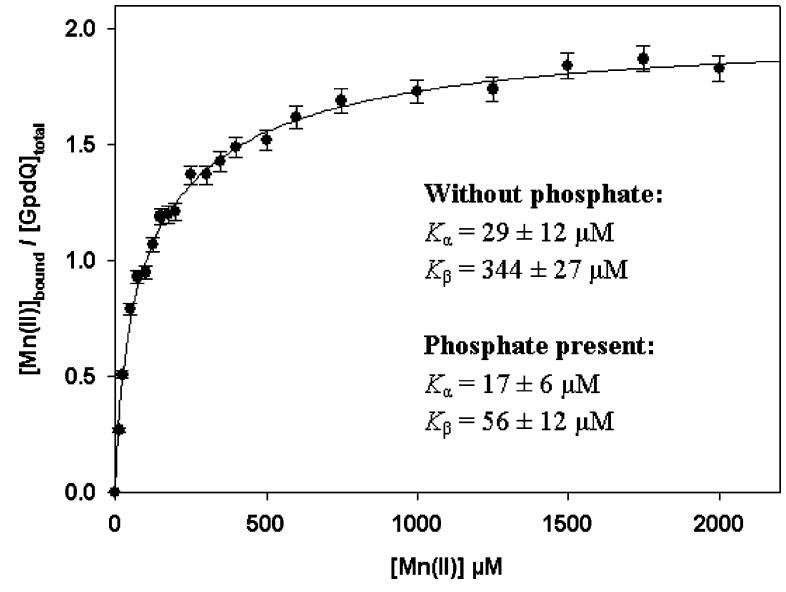

Figure 2. Monitoring of the metal-ion affinity using EPR. Only the data collected in the absence of the substrate analogue phosphate are shown. Qualitatively similar data were obtained in the presence of phosphate, and both data sets were fit to eq 1 .

\section{Scheme 1}

$$
\mathrm{E}+\mathrm{M} \stackrel{K_{1}}{\rightleftharpoons} \mathrm{EM}+\mathrm{M} \stackrel{K_{2}}{\rightleftharpoons} \mathrm{EM}_{2}
$$

Continuous wave (cw) EPR spectra were recorded with a Bruker Elexsys E580 continuous wave/pulsed EPR spectrometer fitted with an X-band Super High Q cavity. The magnetic field and microwave frequency were calibrated with a Bruker ER 036 M Teslameter and a Bruker microwave frequency counter, respectively. A Bruker flowthrough AquaX cell was used to perform the Mn(II) binding titrations. At $20^{\circ} \mathrm{C}$, the aquated $\mathrm{Mn}$ (II) ion displays a typical sextet centered at $g=2$, and the intensity of the resonances reflects the concentration of $\mathrm{Mn}(\mathrm{II})$ ions. Upon binding $\mathrm{Mn}(\mathrm{II})$ to GpdQ, EPR signals were observed only from aquated (free) $\mathrm{Mn}$ (II), as EPR spectra from protein-bound $\mathrm{Mn}(\mathrm{II})$ ions are not observable under these conditions. The highly anisotropic and slow tumbling of the large $\mathrm{Mn}$-protein complex broadens out the EPR resonances at room temperature. Standard curves of $[\mathrm{Mn}(\mathrm{II})]$ versus signal intensity were obtained by recording EPR spectra of samples with varying $\mathrm{Mn}$ (II) concentrations from $10 \mu \mathrm{M}$ to $1 \mathrm{mM}$ in HEPES buffer $\left(100 \mathrm{mM}\right.$ ) at $20^{\circ} \mathrm{C}$ (a titration of $\mathrm{Mn}$ (II) into buffer without enzyme indicated that HEPES did not form complexes with Mn(II)). The plot of peak-to-peak intensities versus [Mn(II)] for any of the resonances of the sextet in the characteristic Mn(II) EPR spectrum resulted in a straight line.

To determine the affinity of GpdQ for Mn(II), EPR spectra were recorded under experimental conditions identical to those used to obtain the standard curve (peak-to-peak intensity vs [Mn(II)]). The protein sample was placed in a Bruker super high-Q cavity and circulated continuously (by peristaltic pump) through an AquaX flow cell $(1.2 \mathrm{~mL})$ equilibrated at $20^{\circ} \mathrm{C}$. $\mathrm{A} \mathrm{MnCl}_{2}$ solution $(10$ $\mu \mathrm{M}$ to $1 \mathrm{mM}$ ) was titrated into the protein sample, and EPR spectra were recorded after $10 \mathrm{~min}$ for each titration point. Because Mn(II) bound to the enzyme does not contribute to the EPR spectrum, at each $\mathrm{Mn}(\mathrm{II})$ concentration the amount of bound metal ions $\left([\mathrm{Mn}(\mathrm{II})]_{\text {bound }}\right)$ was calculated from the difference in EPR signal intensity between the standard solution ([Mn(II) $\left.]_{\text {total }}\right)$ and the relevant protein sample $\left([\mathrm{Mn}(\mathrm{II})]_{\text {free }}\right)$. The ratio $[\mathrm{Mn}(\mathrm{II})]_{\text {bound }} /[\mathrm{E}]_{\text {total }}$ was plotted against $[\mathrm{Mn}(\mathrm{II})]_{\text {total }}$ (Figure 2 ). The data could not be fit to a model for two independent binding sites. A meaningful fit was achieved to eq 1 , which was derived based on a mechanism that assumes two sequential binding events, as shown in Scheme 1 .

$$
\frac{\left[\mathrm{M}_{\text {bound }}\right]}{\left[\mathrm{E}_{\text {total }}\right]}=\frac{K_{2}[\mathrm{M}]+2[\mathrm{M}]^{2}}{K_{1} K_{2}+K_{2}[\mathrm{M}]+[\mathrm{M}]^{2}}
$$

Steady-State Kinetic Assays. The phosphatase activity of GpdQ toward the substrates para-nitrophenyl phosphate ( $p$ NPP), Et $p$ NPP, and $b p N P P$ was measured spectrophotometrically by monitoring the formation of the product $p$-nitrophenolate at $405 \mathrm{~nm}$. Reactions were measured to less than $5 \%$ of total substrate hydrolysis and were performed as a continuous assay for $\mathrm{pH} 5.5$ and above and as a discontinuous assay below $\mathrm{pH}$ 5.5. For the discontinuous assays, the reactions were quenched by adding $5 \mu \mathrm{L}$ of the reaction mixture to $3 \mathrm{~mL}$ of $0.1 \mathrm{M} \mathrm{NaOH}\left(\varepsilon_{400}=18300 \mathrm{M}^{-1} \mathrm{~cm}^{-1}\right.$ for $p$-nitrophenolate). For the continuous assays, the extinction coefficient of the product $p$-nitrophenolate was determined at each relevant $\mathrm{pH}$ by using a standard solution of $p$-nitrophenol in the same buffer used for the enzymatic assays. Kinetic data were treated by the initial rate method and fit to the Michaelis-Menten equation (eq 2), where $V_{\max }$ and $K_{\mathrm{M}}$ are the maximal rate and Michaelis constant, respectively.

$$
\text { velocity }=\frac{V_{\max }[\mathrm{S}]}{K_{\mathrm{M}}+[\mathrm{S}]}
$$

The $\mathrm{pH}$ dependence of $k_{\text {cat }}$ and $k_{\text {cat }} / K_{\mathrm{M}}$ for Co(II)-GpdQ were reported previously. ${ }^{10}$ Here, the $\mathrm{pH}$ dependence of the catalytic parameters for the $\mathrm{Mn}(\mathrm{II})$ - and $\mathrm{Cd}(\mathrm{II})$-derivatives of GpdQ were determined. Where applicable, the following equations, derived for mono- and diprotic systems, respectively, ${ }^{28}$ were used to fit $k_{\text {cat }}$ (eq 3 ) and $k_{\text {cat }} / K_{\mathrm{M}}$ (eq 4 ).

$$
\begin{aligned}
& k_{\text {cat,app }}=\frac{k_{\text {cat }, \mathrm{max}}}{\left(1+\frac{\left[\mathrm{H}^{+}\right]}{K_{\mathrm{es}}}\right)}+k_{\mathrm{cat}, \mathrm{low} \cdot \mathrm{pH}} \\
& \left(\frac{k_{\mathrm{cat}}}{K_{\mathrm{M}}}\right)_{\text {app }}=\frac{\left(\frac{k_{\mathrm{cat}}}{K_{\mathrm{M}}}\right)_{\max }}{\left(1+\frac{\left[\mathrm{H}^{+}\right]}{K_{\mathrm{e} 1}}+\frac{K_{\mathrm{e} 2}}{\left[\mathrm{H}^{+}\right]}\right.}
\end{aligned}
$$

Here, $K_{\text {esi }}$ represents the $\mathrm{i}^{\text {th }}$ protonation equilibrium associated with the enzyme-substrate complex, while $K_{\mathrm{ei}}$ is associated with either the free enzyme or the substrate. ${ }^{28}$

Stopped-Flow Fluorescence and Absorbance Measurements. Stopped-flow experiments were performed using an Applied Photophysics SX-18 spectrometer. The path length of the observation cell was $2.0 \mathrm{~mm}$, and the excitation and emission slits were both set to $2.0 \mathrm{~mm}$; all measurements were carried out at least in triplicate. For fluorescence measurements, the excitation wavelength was set to $260 \mathrm{~nm}$, and the emission at $310 \mathrm{~nm}$ was monitored. The data were recorded at the photomultiplier voltage at which intrinsic fluorescence of the protein (in the absence of substrate) was set equal to $8 \mathrm{~V}$. For absorbance measurements, the protein sample (without substrate) was used as a zero-absorption reference, and the change in absorbance was monitored at $405 \mathrm{~nm}$. The reaction was initiated by injecting equal volumes of substrate (syringe A) and protein (syringe B) to a total volume of $\sim 65 \mu \mathrm{L}$. The protein solution contained $5 \mu \mathrm{M}$ GpdQ and $200 \mu \mathrm{M}$ $\mathrm{CoCl}_{2} \cdot 6 \mathrm{H}_{2} \mathrm{O}$. Both the substrate and protein solutions were buffered with Chelex-treated $50 \mathrm{mM}$ MES, pH 5.5. The extent to which the rate of change in fluorescence depended on substrate concentration was measured under pseudo-first-order conditions ([S] $\gg[\mathrm{E}]$ ).

Data in which the observed rate $\left(k_{\text {obs1 }}\right.$ and $\left.k_{\text {obs2 }}\right)$ exhibited saturation-type dependence on substrate concentration were fit to eq 5 .

(28) Cleland, W. W. Adv. Enzymol. Relat. Areas Mol. Biol. 1977, 45, $273-$ 387. 


$$
k_{\mathrm{obs}}=\frac{k_{\mathrm{f}}[\mathrm{S}]}{K+[\mathrm{S}]}+k_{\mathrm{r}}
$$

Here, $k_{\mathrm{f}}$ and $k_{\mathrm{r}}$ represent first-order rate constants $\left(\mathrm{s}^{-1}\right)$ for substrate binding and release, respectively, while $K$ is the dissociation constant for the preceding step. ${ }^{29,30}$

Data in which an increase in [S] led to a decrease in $k_{\text {obs }}\left(k_{\text {obs3 }}\right)$ were fit as described in the text.

Magnetic Circular Dichroism. MCD spectra were recorded at a $2 \mathrm{~nm}$ bandwidth with a Jasco J-600 spectropolarimeter equipped with an Oxford SM-4 magnet/cryostat and an Oxford ITC-4 temperature controller. Protein samples were diluted with glycerol to a ratio of 3 parts glycerol to 2 parts protein solution and stirred for at least $1 \mathrm{~h}$. The final concentration of protein was in the range 0.68 to $1.09 \mathrm{mM}$. Protein solutions were buffered at $\mathrm{pH} 7.0$ with $50 \mathrm{mM}$ HEPES. The samples were added into a brass cell with quartz windows and a $0.62-\mathrm{cm}$ path length. Spectra were collected in the region between 280 to $800 \mathrm{~nm}$.

\section{Results and Discussion}

Substrate Enhances the Binding Affinity of the Metal Ion in the $\boldsymbol{\beta}$ Site. The paramagnetic properties of $\mathrm{Mn}(\mathrm{II})$ at room temperature (i.e., a characteristic isotropic sextet signal if unbound, EPR-silent if bound) make this metal ion a suitable probe to quantitate the metal-ion binding affinities of the $\alpha$ and $\beta$ sites in the catalytic center of GpdQ. Figure 2 shows the fraction of bound $\mathrm{Mn}(\mathrm{II})$ as a function of added Mn(II). The limiting value is 2 , which indicates two binding events. These data could not be fit to a model for two independent binding sites but instead required an equation derived for a model that assumes stepwise binding of the two ions (i.e., the binding of the first metal ion is required to promote binding of the second; Scheme 1). A metal ion binds to the more strongly coordinating $\alpha$ site, providing an additional ligand (a terminal water ligand that becomes the $\mu$-hydr(oxide) molecule in the binuclear species) for the $\beta$ metal ion, thus enabling the second metal ion to bind. From the fit to the data (Figure 2), the dissociation constants are $K_{\alpha}=29( \pm 12) \mu \mathrm{M}$ and $K_{\beta}=344( \pm 27) \mu \mathrm{M}$. When phosphate (10 equiv) was added, the binding constant of the $\beta$ metal ion changed to $56( \pm 12) \mu \mathrm{M}$, while that of the $\alpha$ site did not change greatly $(17( \pm 6) \mu \mathrm{M})$. The affinity of the metal ions was also assessed by measuring the catalytic activity as a function of the concentration of added $\mathrm{Mn}(\mathrm{II})$. A single binding event was obtained with a $K_{\mathrm{d}}$ of $\sim 80( \pm 20) \mu \mathrm{M}$ (see Figure S2 for more information), in good agreement with the constant for the $\beta$ metal ion in the presence of $\mathrm{PO}_{4}$, as obtained using room temperature EPR. Using a similar approach, it was shown previously that the $K_{\mathrm{d}}$ for the $\beta$ metal ion of the $\mathrm{Co}(\mathrm{II})$ and $\mathrm{Cd}(\mathrm{II})$ derivatives of $\mathrm{GpdQ}$ is 29 and $16 \mu \mathrm{M}$, respectively. ${ }^{10,25}$ Note that because the $K_{\mathrm{d}}$ for the $\mathrm{PO}_{4}-\mathrm{Mn}$ (II) complex is $\sim 15$ $\mathrm{mM},{ }^{31}$ the substrate (or substrate analogue) likely primes the active site for binding of the second metal ion rather than importing this metal in the form of a substrate-metal ion complex.

Formation of a Fully Active Binuclear Metal Center in GpdQ Occurs in Three Stages. Because of the wealth of structural, spectroscopic, and kinetic data available for the $\mathrm{Co}(\mathrm{II})$-derivative of GpdQ, this form of the enzyme was used

(29) Fersht, A. In Enzyme Structure and Mechanism; W. H. Freeman: New York; San Francisco, 1977; Chapter 4, pp 103-133.

(30) Spencer, J.; Clarke, A. R.; Walsh, T. R. J. Biol. Chem. 2001, 276, 33638-33644.

(31) White, D. J.; Reiter, N. J.; Sikkink, R. A.; Yu, L.; Rusnak, F. Biochemistry 2001, 40, 8918-8929.

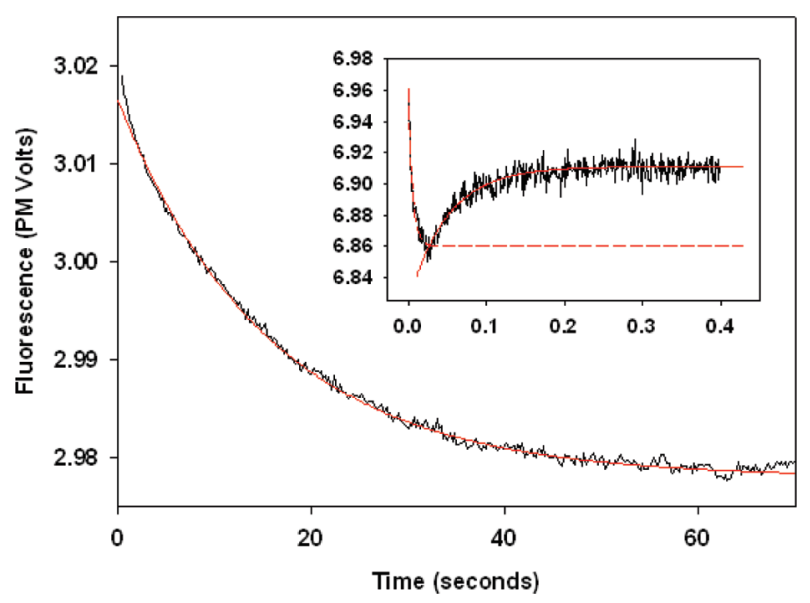

Figure 3. Sample progress curves showing the three fluorescence transient phases of the reaction between GpdQ and the substrate $b p N P P$ (see Supporting Information for a similar data set with the monoester substrate $p$ NPP). Main figure: $5 \mu \mathrm{M}$ GpdQ was reacted with $1.1 \mathrm{mM} b p \mathrm{NPP}$, and the progress was monitored over $70 \mathrm{~s}$. Inset: $5 \mu \mathrm{M}$ GpdQ was reacted with $120 \mu \mathrm{M} b p \mathrm{NPP}$, and fluorescence changes were monitored over $400 \mathrm{~ms}$.

to investigate the early processes of the catalytic reaction. The existing mechanistic model implies that the assembly of a catalytically competent binuclear center requires substratepromoted structural changes in the active site of GpdQ. ${ }^{10}$ Because the intrinsic fluorescent properties of tryptophan and tyrosine residues are suitable probes to monitor conformational changes and/or enzyme-ligand interactions, stopped-flow fluorescence measurements were carried out to investigate the effect of substrate binding (note that similar measurements with the $\mathrm{Mn}(\mathrm{II})$ - and $\mathrm{Cd}(\mathrm{II})$-derivatives were not possible, because these forms of $\mathrm{GpdQ}$ require higher $\mathrm{pH}$ for activity, at which protein precipitation occurs readily under conditions required for the stopped-flow measurements). The excitation wavelength characteristic for tryptophan residues $(\sim 290 \mathrm{~nm})$ resulted only in weak fluorescence changes (data not shown; no Trp residues are in the vicinity of the active site of $\mathrm{GpdQ}^{10}$ ). However, at an excitation wavelength of $260 \mathrm{~nm}$, optimal for tyrosine residues, a strong response was detected (there are four Tyr in the immediate vicinity of the active site: Tyr19, Tyr229, Tyr230, and Tyr263). Control experiments demonstrated that the observed fluorescence changes described below are solely due to the interaction between GpdQ and substrate and not due to mixing or dilution effects (data not shown). Qualitatively, similar results were obtained when $b p \mathrm{NPP}$, Et $p$ NPP, or $p$ NPP were used, and for illustrative purposes only those results acquired with $b p N P P$, one of the diester substrates, are shown here (for data collected with the monoester substrate $p$ NPP, see Supporting Information, Figure S3).

Three distinct changes in fluorescence were observed over a 1-min period in the reaction between $\mathrm{Co}(\mathrm{II})-\mathrm{GpdQ}$ and the substrate. An initial, rapid decrease in fluorescence intensity is followed by a slower increase; finally, a second but slower decrease is then detected (Figure 3). The first two phases are complete within $\sim 200 \mathrm{~ms}$ after initiating the reaction (Figure 3 , inset). The three regions of the observed time course could each be fit separately to a single exponential function $(f(x)=$ $\left.a \exp \left(-k_{\mathrm{obs}} x\right)+c\right)$, resulting in first-order rate constants $k_{\mathrm{obs}(i)}$ ( $i=1,2$, or 3 for the first, second, or third transient, respectively). Because substrate is essential to form a catalytically active site, the effect of substrate concentration on the three transient phases was investigated by measuring $k_{\mathrm{obs}}$ at various 


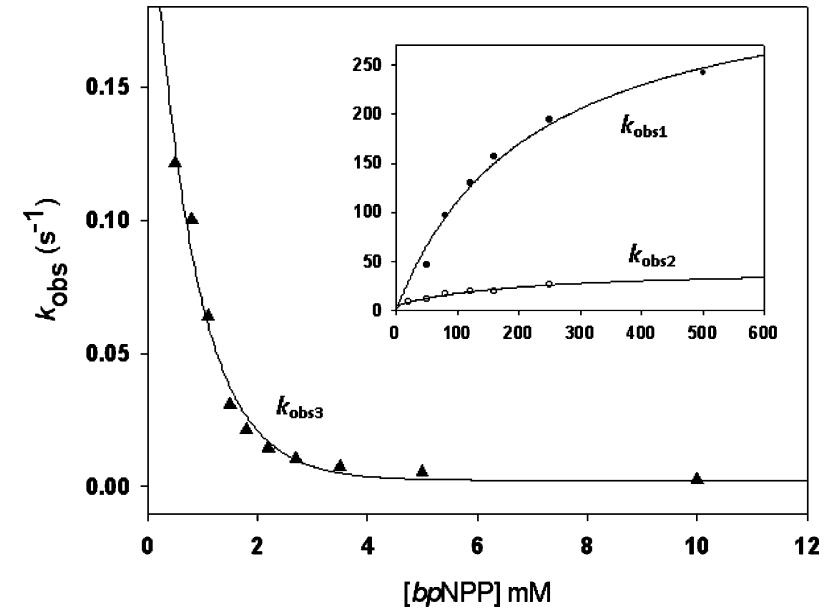

Figure 4. Effect of the substrate concentration ([S]) on the observed rates $\left(k_{\text {obs }}\right)$ associated with the three fluorescence transients. The data were fit to equations described in the text, and the resulting parameters are listed in Table 1.

Table 1. Kinetic Parameters for the Three Transients Observed in the Reaction between GpdQ and bpNPP by Stopped-Flow Fluorescence

\begin{tabular}{clll}
\hline transient & \multicolumn{1}{c}{$k_{\mathrm{f}}$} & \multicolumn{1}{c}{$k_{\mathrm{r}}$} & \multicolumn{1}{c}{$k$} \\
\hline $\mathbf{1}$ & $354 \mathrm{~s}^{-1}$ & $\sim 0$ & $21 \mu \mathrm{M}$ \\
$\mathbf{2}$ & $38 \mathrm{~s}^{-1}$ & $5 \mathrm{~s}^{-1}$ & $206 \mu \mathrm{M}$ \\
$\mathbf{3}$ & $25 \mathrm{~s}^{-1} \mathrm{M}^{-1 a}$ & $\sim 0$ & -
\end{tabular}

${ }^{a}$ The rate constant represents $k_{\mathrm{f}} / K_{\mathrm{I}}$ (see text for details).

Scheme 2

$$
\begin{gathered}
\mathrm{E}_{\mathrm{M}}+\mathrm{S} \underset{K_{1}}{\rightleftharpoons} \mathrm{E}_{\mathrm{M}} \cdot \mathrm{S} \underset{\substack{k_{1 \mathrm{r}} \\
K_{2}}}{\stackrel{k_{1 \mathrm{f}}}{\rightleftharpoons}} \mathrm{E}_{\mathrm{M}} \cdot \mathrm{S} \underset{k_{2 \mathrm{r}}}{\stackrel{k_{2 \mathrm{f}}}{\rightleftharpoons}} \mathrm{E}_{\mathrm{B}} \cdot \mathrm{S} \underset{K_{\mathrm{I}}}{\stackrel{k_{3 \mathrm{f}}}{\rightleftharpoons}} \mathrm{E}_{\mathrm{B}}{ }^{*} \cdot \mathrm{S} \\
\mathrm{S} \cdot \mathrm{E}_{\mathrm{B}} \cdot \mathrm{S}
\end{gathered}
$$

[S]. Figure 4 summarizes the data and shows that $k_{\mathrm{obs} 1}$ and $k_{\mathrm{obs} 2}$ display a nonlinear behavior, whereby an increase in $[\mathrm{S}]$ leads to a gradual increase in $k_{\mathrm{obs}}$, reaching a maximal value at high concentration ( $k_{\mathrm{obs} 3}$ behaves differently and is discussed below). The data for $k_{\mathrm{obs} 1}$ and $k_{\mathrm{obs} 2}$ were fit to eq 5 , which is derived for a simple bimolecular reaction, and the resulting parameters are listed in Table 1. A similar behavior (i.e., a rapid loss of fluorescence followed by a slower regain in intensity) is also observed for the binuclear L1 metallo- $\beta$-lactamase from Stenotrophomonas maltophilia and was interpreted in terms of a minimal reaction scheme in which an initial binding of substrate was followed by slower rearrangements. ${ }^{30}$ For GpdQ, in Scheme 2 (above) is proposed, in which $\mathrm{E}_{\mathrm{M}}$ and $\mathrm{E}_{\mathrm{B}}$ correspond to mononuclear (M) and binuclear (B) enzyme forms, and $k_{\mathrm{f}}$ and $k_{\mathrm{r}}$ are the on and off rates, respectively, for the reactions associated with the individual changes in fluorescence intensity (i.e., $k_{\mathrm{obs} 1}, k_{\mathrm{obs} 2}$, and $k_{\mathrm{obs} 3}$ ).

Following rapid formation of an $\mathrm{E}_{\mathrm{M}} \bullet \mathrm{S}$ complex, the substrate rearranges in the active center to prime the $\beta$ site (Figure 1 ) for metal-ion binding $\left(\mathrm{E}_{\mathrm{M}^{\prime}} \bullet \mathrm{S}\right)$, a process that is virtually irreversible ( $k_{1 \mathrm{r}}$ close to 0 ; Table 1 ). Upon binding of the metal ion, a catalytically competent binuclear enzyme-substrate complex $\left(E_{B} \bullet S\right.$ ) is formed with a rate of $\sim 40 \mathrm{~s}^{-1}$ (Table 1), a rate that is approximately 40 -fold higher than the turnover number $\left(k_{\text {cat }}\right)$ for hydrolysis of $b p \operatorname{NPP}\left(\sim 1 \mathrm{~s}^{-1}\right)$. Thus, the processes that lead up to the formation of a binuclear center in the active site of GpdQ are unlikely to contribute to the rate-limiting step.

In contrast to this behavior of $k_{\mathrm{obs} 1}$ and $k_{\mathrm{obs} 2}$, an increase of [S] leads to a decrease in $k_{\text {obs } 3}$ (Figure 4). ${ }^{32}$ Although the observation of a third transient implies that the $E_{B} \bullet S$ complex is rearranged further, the inhibitory effect of $[\mathrm{S}]$ is also reminiscent of that observed, for instance, in the reaction between another binuclear metallohydrolase, uteroferrin, and one of its substrate analogues (phosphate). ${ }^{33}$ In that study, the inhibitory effect of phosphate on $k_{\text {obs }}$ was interpreted in terms of the binding of a second molecule of substrate as shown in Scheme $2:{ }^{34}$

An equation for the [S] dependence of $k_{\mathrm{obs}}$ is of the type

$$
k_{\mathrm{obs} 3}=\frac{k_{3 \mathrm{f}} A[\mathrm{~S}]}{B[\mathrm{~S}]^{2}+C[\mathrm{~S}]+1}+k_{3 \mathrm{r}}
$$

where $A, B$, and $C$ represent fitting parameters. ${ }^{33}$ The data for $k_{\text {obs3 }}$ cannot be unambiguously fit to this equation. However, $k_{3 \mathrm{r}}$ can be estimated, because, for high levels of [S], eq 6 simplifies to eq 7 :

$$
k_{\mathrm{obs} 3}=\frac{k_{3 \mathrm{f}} A}{B} \frac{1}{[\mathrm{~S}]}+k_{3 \mathrm{r}}
$$

The ratio A/B can be shown to correspond to $1 / K_{\mathrm{I}}{ }^{33}$ where $K_{\mathrm{I}}$ is the dissociation constant for the binding of the second substrate molecule to GpdQ (Scheme 2), and thus eq 7 can be rewritten as

$$
k_{\mathrm{obs} 3}=\frac{k_{3 \mathrm{f}}}{K_{\mathrm{I}}} \frac{1}{[\mathrm{~S}]}+k_{3 \mathrm{r}}
$$

The parameters from a fit to eq 8 , listed in Table 1 , indicate that the structural rearrangement is slow and virtually irreversible $\left(k_{3 \mathrm{r}} \approx 0\right)$. Although obtaining an accurate estimate for $k_{3 \mathrm{f}}$ is not presently possible, the observed rates for the structural change ( $k_{\text {obs } 3}$; Figure 4 ) suggest that as [S] increases, this rearrangement may become increasingly more important in the rate-limiting step.

To correlate the observed fluorescence changes to catalytic steps in the mechanism of phosphorolysis, the reaction between GpdQ and $b p$ NPP was monitored by stopped-flow absorbance measurements. Absorbance changes were measured at $405 \mathrm{~nm}$, the wavelength optimal for detecting the nitrophenolate product of the hydrolytic reaction (see Figure S5). The absorbance changes measured over several minutes were used to calculate the turnover number for the hydrolysis of $b p \mathrm{NPP}\left(k_{\mathrm{cat}} ; \mathrm{s}^{-1}\right)$, and the corresponding stopped-flow fluorescence data measured for the same reaction are also shown in Figure 5. The $k_{\text {cat }}$ gradually increases, reaching a maximum value after $\sim 100 \mathrm{~s}$ ( $2 \mathrm{mM} b p \mathrm{NPP})$. The subsequent decrease in $k_{\text {cat }}$ corresponds to

(32) For comparison, the dependence of $k_{\mathrm{obs}(\mathrm{i})}(i=1,2,3)$ on the concentration of the monoester substrate $p$ NPP is shown in Figure S4. The overall behavior of the three transients are identical to that observed for $b p$ NPP.

(33) Twitchett, M. B.; Schenk, G.; Aquino, M. A. S.; Yiu, D. T. Y.; Lau, T. C.; Sykes, A. G. Inorg. Chem. 2002, 41, 5787-5794.

(34) Note that, in principle, the observed inhibition may also arise from product inhibition. However, several observations favor the proposed substrate inhibition: (i) qualitatively similar fluorescence data were measured for both mono-and diester substrates; (ii) the product of the diester reaction is the monoester substrate $(p N P P)$, which has low binding affinity and is turned over slowly; (iii) the product of the monoester reaction is the rather potent inhibitor $\mathrm{PO}_{4}$. 


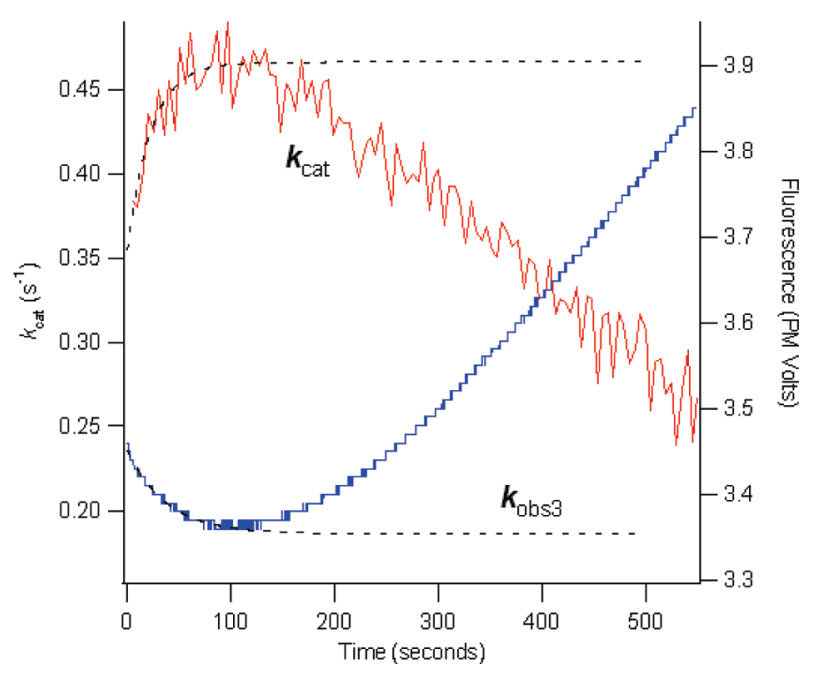

Figure 5. Progress curves for the reaction between GpdQ and $b p N P P(2$ $\mathrm{mM})$. Upper curve: the $k_{\mathrm{cat}}$ reaches a maximum after $\sim 100 \mathrm{~s}$. Lower curve: the third fluorescence transient $\left(k_{\text {obs } 3}\right)$ is complete after $\sim 100 \mathrm{~s}$, the time at which $k_{\text {cat }}$ maximizes. After $\sim 150 \mathrm{~s}$, the $k_{\text {cat }}$ reduces, and the fluorescence starts to rise again as the substrate is being depleted; the enzyme gradually returns to its inactive mononuclear form.

the gradual depletion of substrate. Interestingly, changes in the fluorescence behavior follows an identical time course; in the first $\sim 100 \mathrm{~s}$ of the reaction, the fluorescence quenches (with a rate characterized by $k_{\mathrm{obs} 3}$ ) and then gradually regains intensity as substrate is used up and the enzyme returns to its resting state. Hence, $k_{\mathrm{obs} 3}$ (Scheme 2) is ascribed to the rearrangement of $\mathrm{E}_{\mathrm{B}} \cdot \mathrm{S}$, a modestly active complex, to a more reactive one $\left(\mathrm{E}_{\mathrm{B}} * \cdot \mathrm{S} ;\right.$ Scheme 2$)$.

The combined stopped-flow data thus invoke a mechanistic model whereby rapid binding of substrate to an inactive form of GpdQ $\left(\mathrm{E}_{\mathrm{M}}\right)$ is followed by rearrangement of the resulting $\mathrm{E}_{\mathrm{M}} \bullet \mathrm{S}$ complex to a moderately active $\mathrm{E}_{\mathrm{B}} \bullet \mathrm{S}$ complex. This complex can undergo further conformational changes to become more reactive, but the binding of a second substrate molecule, presumably in the vicinity of the active site, may prevent this rearrangement. These steps, illustrated in Scheme 2, can be reconciled with previously invoked catalytic steps. After initial rapid binding of the substrate to the enzyme (forming the $\mathrm{E}_{\mathrm{M}} \bullet \mathrm{S}$ complex), $k_{\mathrm{obs} 1}$ describes the rearrangement of the still mononuclear $\left(\mathrm{E}_{\mathrm{M}}\right)$ active site to prime it for the binding of the second metal ion $\left(\mathrm{E}_{\mathrm{M}^{\bullet}} \cdot \mathrm{S}\right)$. Following the binding of the second metal ion, a moderately active binuclear $\mathrm{E}_{\mathrm{B}} \bullet \mathrm{S}$ complex is formed $\left(k_{\mathrm{obs} 2}\right.$; Scheme 2). Previous studies using MCD spectroscopy indicated that flexible coordination by the $\beta$ metal-ion ligand Asn80 (Figure 1) may regulate enzymatic activity once the binuclear active center has been assembled. ${ }^{10}$ The third transient phase in the reaction between GpdQ and substrate $\left(k_{\text {obs } 3}\right)$ is thus interpreted as a break in the coordination bond between the $\beta$ metal ion and Asn80 and a concomitant rearrangement of the active-site geometry and/or substrate orientation (mediated by the hydrogen-bond network that connects Asn80 with the substrate binding pocket). The significance of coordination flexibility in regulating and optimizing the catalytic efficiency of GpdQ is also demonstrated when the two mutants Asn80Ala and Asn80Asp are investigated by stopped-flow fluorescence. Both mutants have been shown to have greatly reduced catalytic efficiency in comparison to the wild-type enzyme. ${ }^{10}$ In the alanine mutant $k_{\mathrm{obs} 1}$ is not observed and $k_{\mathrm{obs} 2}$ and $k_{\mathrm{obs} 3}$ are slower than in the wild-type enzyme (Figure S6). In the aspartate mutant, the least reactive form of GpdQ, no fluorescence transients are observed (Figure S7), supporting the above interpretation of the individual transients observed in the reaction catalyzed by wild-type GpdQ. $k_{\mathrm{obs} 1}$ and $k_{\mathrm{obs} 2}$ are associated with structural changes that occur (i) in the mononuclear enzyme, preparing it for binding of the second metal ion, and (ii) during the binding of the second metal with the concomitant formation of a binuclear center, respectively; $k_{\mathrm{obs} 3}$ arises from the flexible coordination of ligand Asn80. In the Asn80Asp mutant, the second metal ion remains tightly bound throughout the catalytic cycle and the Asp80 ligand does not display coordination flexibility. Thus, the lack of fluorescence transients suggests that the active site in this mutant lacks structural flexibility, reflecting its reduced reactivity.

The above assignment of $k_{\mathrm{obs} 3}$ to a gradual structural rearrangement required to attain optimal activity may also indicate that the $\beta$ metal ion remains bound to the active site as long as substrate is available for the reaction. While the catalytic turnover number is on the order of $1 \mathrm{~s}^{-1}$, it takes $\sim 100 \mathrm{~s}$ for the activity to reach its maximum (Figure 5). Thus, once an activated $\mathrm{E}_{\mathrm{B}}$ * complex has been formed it remains present until substrate is depleted, upon which the occupancy of the $\beta$ metalion site gradually decreases and the active site returns to its mononuclear $\mathrm{E}_{\mathrm{M}}$ state (Scheme 2).

Role of the Hydrogen-Bond Network in Regulating the Coordination of the $\boldsymbol{\beta}$ Metal Ion. The three stages described in the previous section demonstrate that structural changes occur throughout the catalytic cycle of GpdQ, but the question of how these rearrangements are mediated remains. The likely mechanism involves interactions between substrate and the $\mathrm{H}$-bond network that connects the first and second coordination spheres. This network includes two histidine residues, His 81 and His217. ${ }^{10}$ Measuring the $\mathrm{pH}$ dependence of the catalytic efficiency $\left(k_{\text {cat }} / K_{\mathrm{M}}\right)$ of $\mathrm{Co}$ (II)-GpdQ demonstrated the presence of a catalytically relevant $\mathrm{p} K_{\mathrm{a}}$ at $\sim 7.0^{10}$ that was, tentatively, ascribed to one of those two histidines. Here, we have shown that replacement of these residues by alanines does not affect this $\mathrm{p} K_{\mathrm{a}}$ value substantially (Figure 6). Furthermore, although the $k_{\text {cat }}$ does not display a strong dependence on $\mathrm{pH}$, the His81Ala and His217Ala mutations lead to a moderate decrease and increase in the turnover rate, respectively (e.g., at pH 7.0 with the substrate $b p N P P$, the $k_{\text {cat }}$ values for wild-type, His81Ala, and His217Ala GpdQ are 1.4, 0.6, and $4.9 \mathrm{~s}^{-1}$, respectively). Thus, the catalytically relevant $\mathrm{p} K_{\mathrm{a}}$ of $\sim 7.0$ is not likely to correspond to one of these two histidine residues. Figure 7 shows the MCD spectra for the two GpdQ mutants in the absence and presence of the substrate analogue phosphate (using $\mathrm{Co}$ (II) for reconstitution). For comparison, the previously reported ${ }^{10}$ spectrum for the wild-type enzyme is also included. In the wildtype spectrum, when 2 equiv of $\mathrm{Co}(\mathrm{II})$ were added to GpdQ, only one metal ion was bound (a six-coordinate species in the $\alpha$ site). ${ }^{10}$ When phosphate was added, both metal-ion binding sites became occupied. In contrast, both histidine-to-alanine mutants have considerable affinity for the metal ion in the $\beta$ site, even in the absence of phosphate, as demonstrated by the

(35) Kaden, T. A.; Holmquist, B.; Vallee, B. L. Biochem. Biophys. Res. Commun. 1972, 46, 1654-1659.

(36) Larrabee, J. A.; Chyun, S. A.; Volwiler, A. S. Inorg. Chem. 2008, 47, 10499-10508.

(37) Larrabee, J. A.; Leung, C. H.; Moore, R. L.; Thamrong-Nawasawat, T.; Wessler, B. S. H. J. Am. Chem. Soc. 2004, 126, 12316-12324.

(38) Lever, A. B. P. Inorganic electronic spectroscopy, 2nd ed.; Elsevier: Amsterdam; Oxford, New York, 1984.

(39) Prescott, J. M.; Wagner, F. W.; Holmquist, B.; Vallee, B. L. Biochemistry 1985, 24, 5350-5356. 


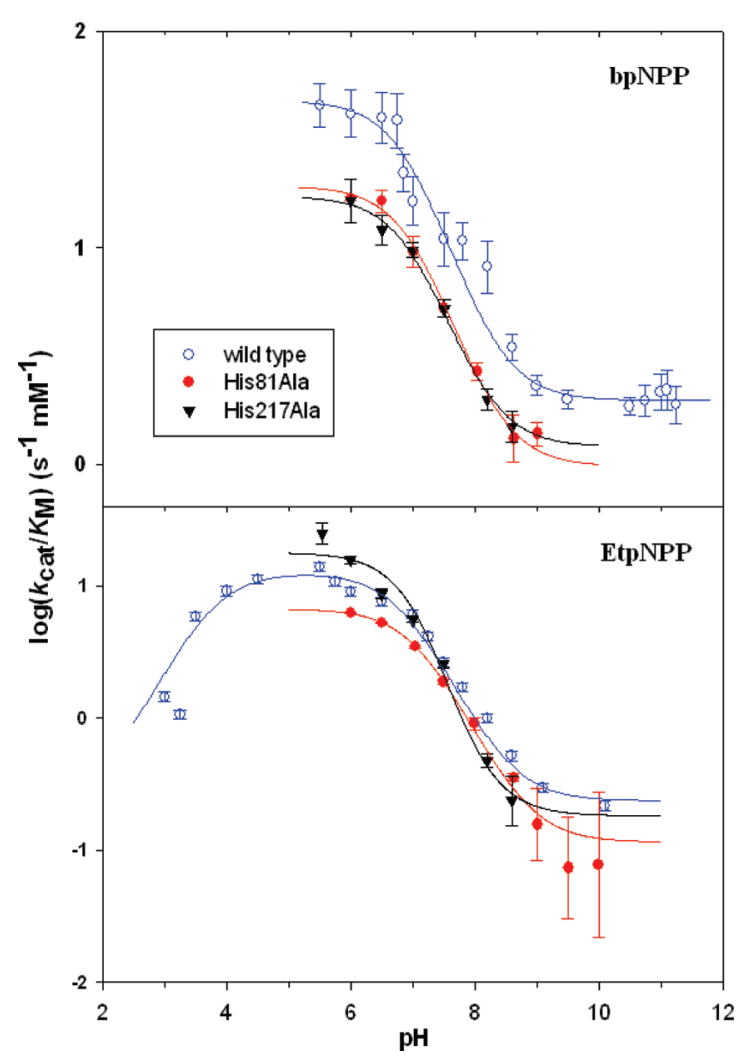

Figure 6. Effect of $\mathrm{pH}$ on the catalytic efficiency $\left(k_{\text {cat }} / K_{\mathrm{M}}\right)$ of wild-type GpdQ and its His81Ala and His217Ala mutants, using $b p$ NPP (top) or Et $p$ NPP (bottom) as substrates. The catalytically relevant $\mathrm{p} K_{\mathrm{a}}$ at $\sim 7.0$ is apparent in each data set. Below pH 6.0, the two mutants lose activity. Hence, the data were fit to equations derived for a monoprotic system for the mutants and for a diprotic one for wild-type GpdQ, as described elsewhere. ${ }^{10}$

presence of the band at $\sim 570 \mathrm{~nm}$, characteristic of a fivecoordinate species ${ }^{10,35-39}$ (based on a comparison of the signal intensities of the $\sim 570 \mathrm{~nm}$ bands, the two mutants have $\sim 2$ (His81Ala) to 8-fold (His217Ala) increased metal-ion binding affinity in comparison to the wild type enzyme; Figure 7). Adding $\mathrm{PO}_{4}$ enhances this affinity further. Thus, although none of these histidine residues interact directly with the metal ions, they are capable of affecting the coordination environment of the $\beta$ metal ion, thus illustrating the importance of the $\mathrm{H}$-bond network in regulating coordination of the metal ion in the $\beta$ site. Since the $K_{\mathrm{M}}$ values (a measure of substrate affinity) are not greatly affected by these two mutations, none of these histidine residues are likely to play a major role in substrate binding. It thus seems likely that the main role for these residues is to mediate $\mathrm{H}$-bond interactions that facilitate both the binding of the second metal ion and the optimal positioning of the substrate, achieved via flexible coordination of Asn80.

Because neither of the two histidines can be assigned to the catalytically relevant protonation equilibrium with a $\mathrm{p} K_{\mathrm{a}}$ of $\sim 7.0$, the question about the identity of the corresponding residue remains. Analysis of the crystal structure of $\mathrm{Co}$ (II)-GpdQ reveals that in two out of six subunits, an additional water ligand is terminally bound to the metal ion in the $\beta$ site (Figure 1 ). ${ }^{10} \mathrm{We}$ tentatively assign $\mathrm{p} K_{\mathrm{a}} \sim 7.0$ to this ligand. Its deprotonated form at $\mathrm{pH}>\mathrm{p} K_{\mathrm{a}}$ would slow down ligand exchange at the $\beta$ site, which may thus interfere with substrate binding, a likelihood consistent with the reduced catalytic efficiency at high $\mathrm{pH}$ (Figure 6). Note that a $\mathrm{p} K_{\mathrm{a}}$ of $\sim 7$ is low for a terminally, Co(II)-

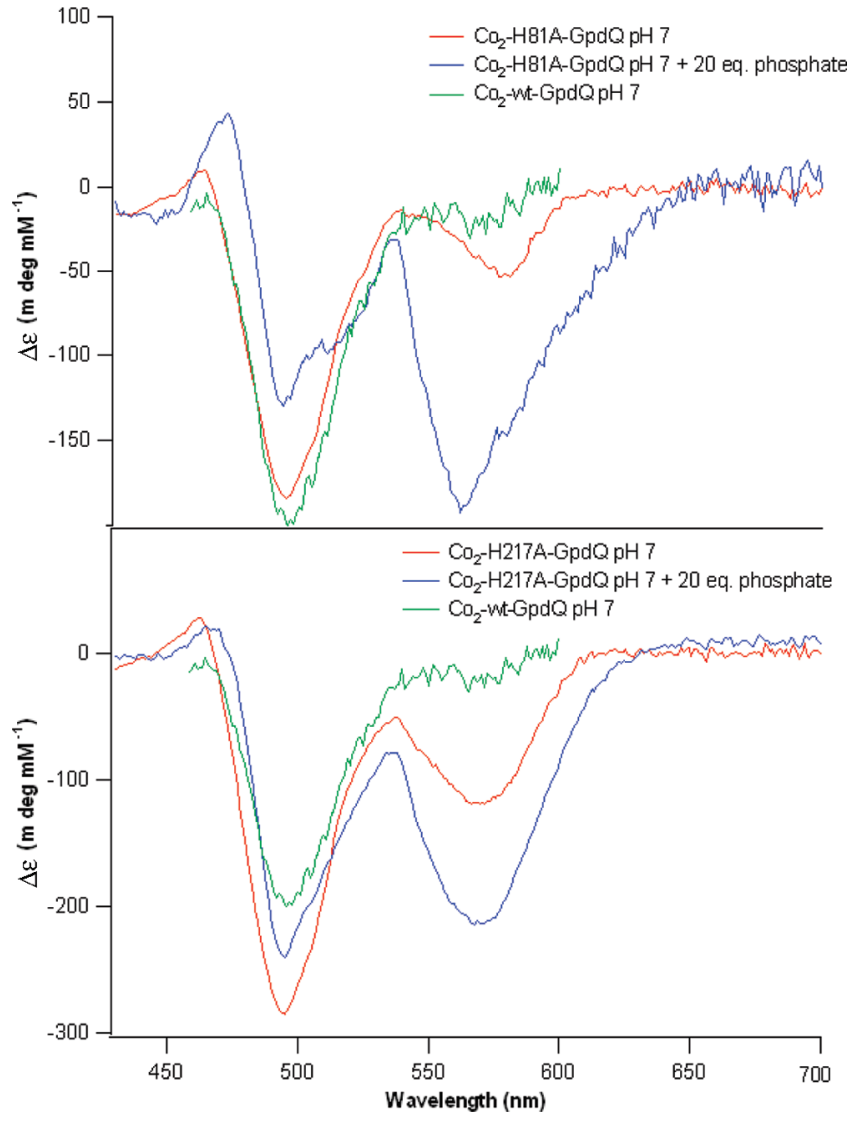

Figure 7. MCD spectra of His81Ala-GpdQ (top) and His217Ala-GpdQ (bottom) in the absence and presence of phosphate. Each sample contains 2 equiv of $\mathrm{Co}(\mathrm{II})$. For comparison, the spectrum of the wild-type enzyme ( 2 equiv $\mathrm{Co}$ (II), no phosphate) is also included. Even in the absence of phosphate, a metal ion can bind to the five-coordinate $\beta$ site only in the two mutant forms of GpdQ.

bound water molecule (the $\mathrm{p} K_{\mathrm{a}}$ of $\left[\mathrm{Co}(\mathrm{II})\left(\mathrm{H}_{2} \mathrm{O}\right)_{6}\right]$ is $\sim 9.6^{40}$ ), but the water ligand bound to the $\beta$ metal ion is within H-bonding distance $(\sim 3 \AA)$ of the amide group of Asn 80 , the metal-ion-bridging hydroxide, and the water molecule coordinated terminally to the $\alpha$ metal ion, which could lower its $\mathrm{p} K_{\mathrm{a}}$ (Figure 1).

Metal Ions and Substrates Modulate the Reaction Mechanism. Although the steps leading up to the formation of a catalytically competent $\mathrm{E}_{\mathrm{B}} \bullet \mathrm{S}$ complex are likely to be largely independent of the identity of the metal ions or substrates, the same may not be the case for the subsequent steps in catalysis. Rearrangement of the $E_{B} \bullet S$ complex to the fully active $E_{B} * \cdot S$ complex is associated with flexible coordination of Asn80, whose time course is described by $k_{\mathrm{obs} 3}$ (vide supra). This time constant (Figure 4) is of a magnitude similar to that of $k_{\text {cat }}$ (Figure 8) and may thus contribute to the overall rate of the reaction. For the $\mathrm{Co}(\mathrm{II})$-derivative of GpdQ, the $k_{\text {cat }}$ in particular for the reaction with the monoester substrate $p$ NPP was shown to be $\mathrm{pH}$ independent, suggesting that the rate-limiting step is not associated with bond breakage but with product release and/ or conformational changes. ${ }^{10}$ Such conformational changes may of course be linked to the flexible coordination in the $\beta$ metalion site. For the reaction with the diester substrates $b p N P P$ and Et $p$ NPP, these conformational changes may also be relevant,

(40) Baes, C. F.; Mesmer, R. E. The hydrolysis of cations; Wiley: New York, 1976. 


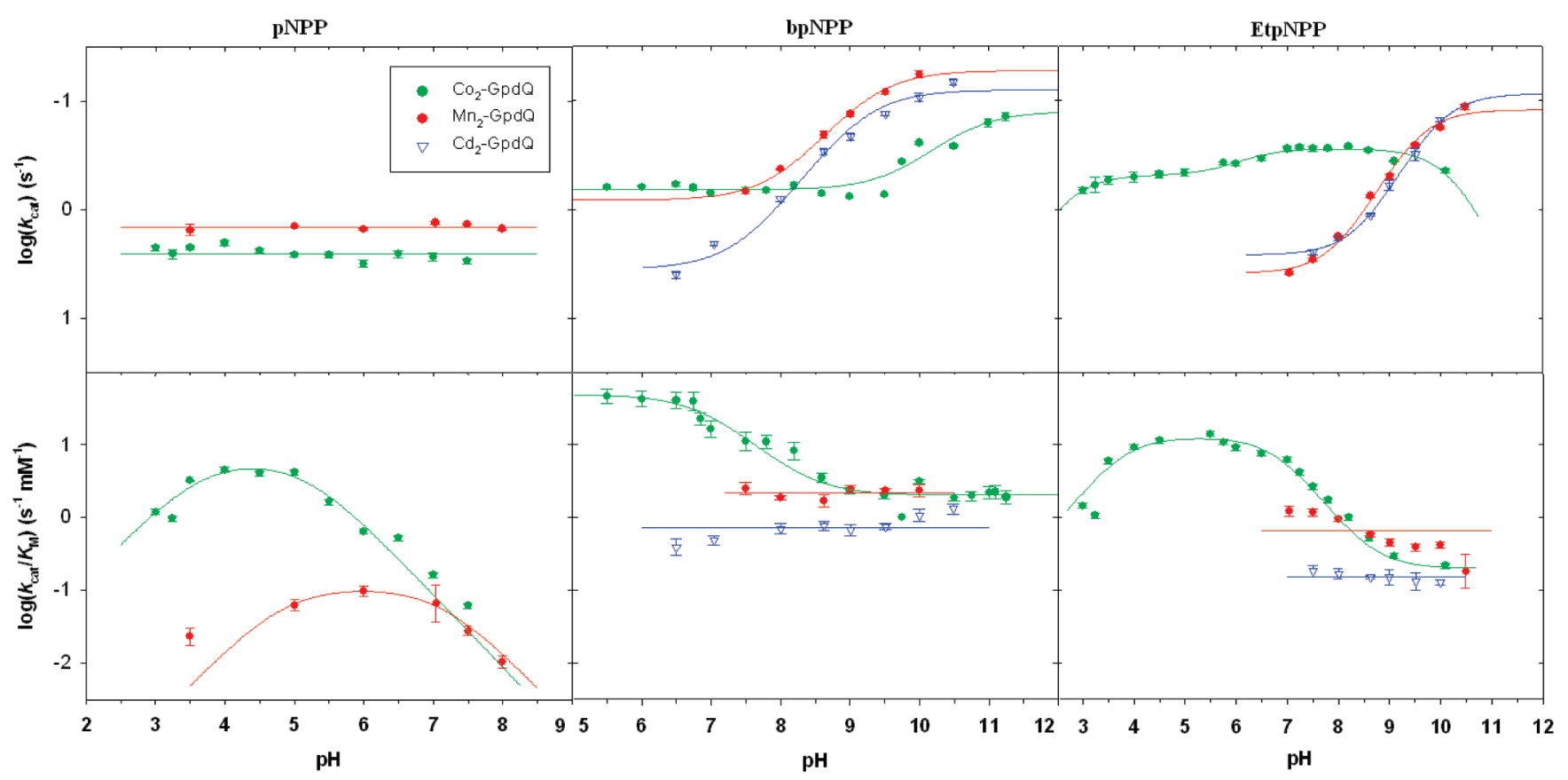

Figure 8. $\mathrm{pH}$ profiles for the hydrolysis of $p \mathrm{NPP}, b p \mathrm{NPP}$, and Et $p \mathrm{NPP}$ for GpdQ reconstituted with $\mathrm{Co}(\mathrm{II}), \mathrm{Mn}(\mathrm{II})$, and Cd(II). Top: $\mathrm{pH}$ dependence of $k_{\text {cat }}$. Bottom: $\mathrm{pH}$ dependence of $k_{\mathrm{cat}} / K_{\mathrm{M}}$.

Table 2. Dissociation Constants ${ }^{a}$ for the Hydrolysis of $b p N P P$, EtpNPP, and $p$ NPP by Co(II)-, Mn(II)-, and Cd(II)-Substituted GpdQ

\begin{tabular}{|c|c|c|c|c|c|c|c|c|c|}
\hline & \multicolumn{2}{|c|}{$p N P P$} & \multicolumn{5}{|c|}{ EtpNPP } & \multicolumn{2}{|c|}{ bpNPP } \\
\hline & $\mathrm{pK} \mathrm{K}_{\mathrm{e} 1}$ & $\mathrm{pK} K_{\mathrm{e} 2}$ & $\mathrm{pK}_{\mathrm{es} 1}$ & $p K_{\text {es2 }}$ & $\mathrm{pK}_{\mathrm{es} 3}$ & $\mathrm{pK}_{\mathrm{e} 1}$ & $\mathrm{pK}_{\mathrm{e} 2}$ & $p K_{\text {es } 1}$ & $p K_{\mathrm{e} 1}$ \\
\hline Co(II)-GpdQ & 3.8 & 5.1 & $<3.2$ & 6.2 & 10.2 & 3.7 & 6.9 & 9.9 & 7.0 \\
\hline Mn(II)-GpdQ & 4.8 & 7.1 & 9.7 & - & - & - & - & 9.2 & - \\
\hline Cd(II)-GpdQ & - & - & 9.8 & - & - & - & - & 9.4 & - \\
\hline
\end{tabular}

${ }^{a}$ The $\mathrm{p} K_{\mathrm{es} n}$ and $\mathrm{p} K_{\mathrm{e} n}(n=1,2$, or 3$)$ values for the $\mathrm{Mn}(\mathrm{II})-$ and $\mathrm{Cd}(\mathrm{II})$-derivatives of GpdQ were obtained from fits of the $\mathrm{pH}$ dependence of the $k_{\text {cat }}$ and $k_{\text {cat }} / K_{\mathrm{M}}$ (Figure 8), respectively. The data for the $\mathrm{Co}(\mathrm{II})$-derivative were published previously. ${ }^{10}$

but $\mathrm{P}-\mathrm{O}$ bond fission is also at least partially rate-limiting. ${ }^{10}$ Furthermore, although a minimum of one protonation equilibrium is relevant to the hydrolysis of $b p N P P$, at least three are required for Et $p$ NPP (Figure 8; Table 2). ${ }^{10}$ Assigning the three $\mathrm{p} K_{\mathrm{a}}$ values has enabled us to propose a catalytic scheme for the hydrolysis of Et $p$ NPP, whereby the metal-ion-bridging hydroxide activates the $\alpha$ metal-ion-bound, nucleophilic hydroxide. Consequently, GpdQ can effectively hydrolyze this diester over a large $\mathrm{pH}$ range (from $\mathrm{pH} 3.0$ to 11 ). ${ }^{10}$ However, the only apparent protonation equilibrium in the reaction with $b p \mathrm{NPP}$ $\left(\mathrm{p} K_{\mathrm{a}}=9.9\right.$; Table 2$)$ suggests that a nonactivated hydroxide (i.e., a hydroxide terminally bound to the metal ion in the $\alpha$ site) may act as the nucleophile. ${ }^{10}$

To probe the effect of the metal-ion composition on the mechanism of hydrolysis, the catalytic properties of the Mn(II)and $\mathrm{Cd}(\mathrm{II})$-derivatives of GpdQ were investigated over a broad $\mathrm{pH}$ range (Figure 8). The $\mathrm{Cd}(\mathrm{II})$-derivative is not an effective monoesterase, but for the diester substrates $b p N P P$ and Et $p$ NPP its catalytic properties are similar to those of $\mathrm{Mn}$ (II)-GpdQ. Although the $k_{\text {cat }} / K_{\mathrm{M}}$ ratios of the two derivatives for the hydrolysis of the diester substrates are virtually independent of $\mathrm{pH}$ (in marked contrast to the $\mathrm{Co}$ (II)-derivative), their turnover numbers display monoprotic behavior, reaching maximum activity at $\mathrm{pH}>9$. The data were fitted to eq 3 , and the parameters are listed in Table 2. The slopes of the $\mathrm{pH}$ profiles are close to 1 , indicating that $\mathrm{P}-\mathrm{O}$ bond fission may be nearly fully rate-limiting. The likely nucleophile is a nonactivated hydroxide bound to the $\alpha$ metal ion. While the reaction between GpdQ and $b p$ NPP is not greatly affected by metal ion substitutions, a replacement of the metal ion does affect the reaction when Et $p$ NPP is the substrate, indicating that both the metal ion and the substrate can affect the catalytic mechanism.

Comparing the monoesterase activity of the $\mathrm{Co}$ (II)- and Mn(II)-derivatives of GpdQ (Figure 8) proved interesting. Although the $k_{\text {cat }}$ values for both derivatives are $\mathrm{pH}$ independent (and their rate-limiting steps thus are not associated with bond breakage), their $k_{\text {cat }} / K_{\mathrm{M}}$ ratios display a bell-shaped behavior, indicating the presence of at least two relevant protonation equilibria associated with the free enzyme, the substrate, or both. The data were fit to eq 4 (see Table 2 for parameters). For the Co(II)-derivative, $\mathrm{p} K_{\mathrm{e} 2}=5.1$ (Table 2) was previously assigned to the second $\mathrm{p} K_{\mathrm{a}}$ of the substrate $p \mathrm{NPP}\left(\mathrm{p} K_{\mathrm{a} 2} \approx 5\right)$, which indicates that this substrate undergoes catalysis preferentially in its monoanionic form. ${ }^{10}$ In the $\mathrm{Mn}(\mathrm{II})$-derivative $\mathrm{p} K_{\mathrm{e} 2}$ is shifted by two units $(\sim 7.1$; Table 2$)$, indicating that this protonation equilibrium is not likely to correspond to the substrate, but rather to the free enzyme. A likely residue is the water molecule terminally bound to the $\beta$ metal ion (as described in the previous section). However, $\mathrm{p} K_{\mathrm{e} 1}(\sim 4.8)$ is close to the second $\mathrm{p} K_{\mathrm{a}}$ of the substrate, suggesting that, in Mn(II)-GpdQ, the monoester substrate undergoes catalysis preferentially in the dianionic form.

\section{Conclusion}

This study demonstrates how the bioremediator GpdQ, a binuclear enzyme of the metallohydrolase family, employs an intricate mechanism for catalysis, whereby the substrate binds to the active site of the enzyme, thus promoting the binding of a second metal ion to the $\beta$ site and leading to the formation of a catalytically relevant binuclear enzyme-substrate $\left(E_{B} \bullet S\right)$ complex. Figure 9 depicts a model for the catalytic cycle employed by this versatile enzyme. The initial steps of catalysis, 
$\mathrm{PO}_{2}(\mathrm{OR})(\mathrm{OR})$

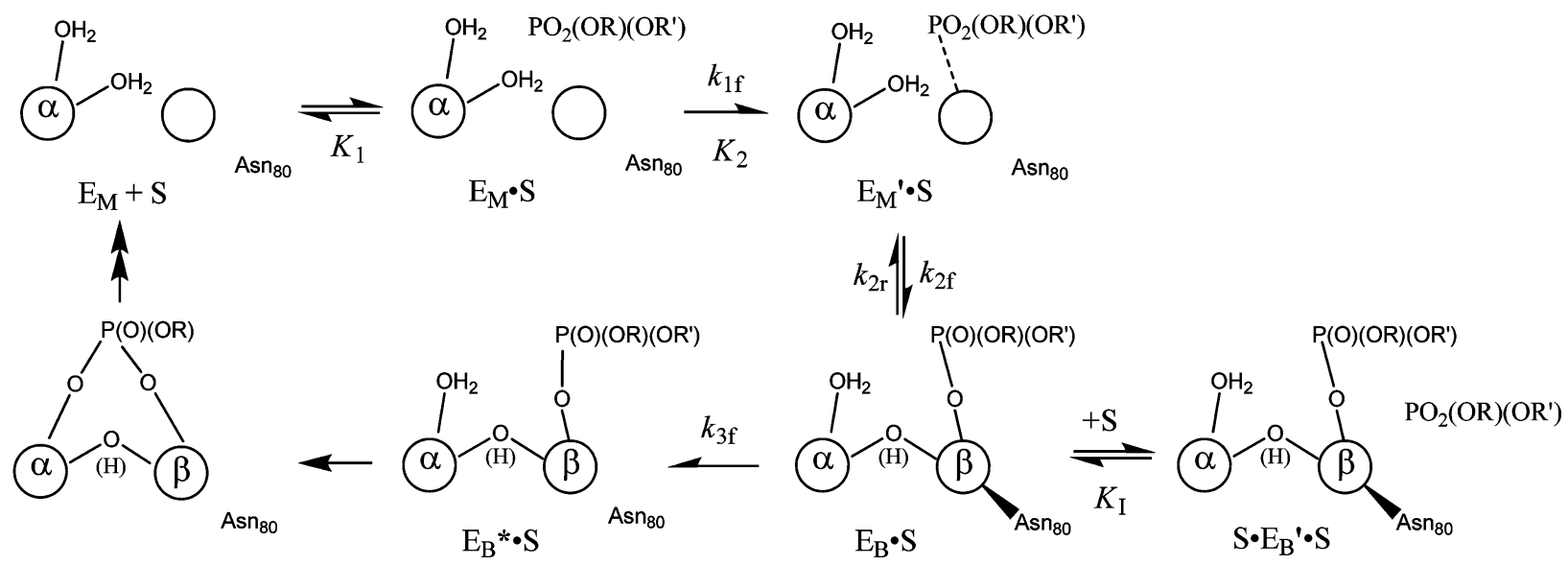

Figure 9. Mechanism of hydrolysis of phosphate esters by GpdQ, as determined from stopped-flow fluorescence studies.

i.e., the steps leading to the assembly of the $\mathrm{E}_{\mathrm{B}} \bullet \mathrm{S}$ complex, are rapid in comparison to the turnover number $\left(k_{\mathrm{cat}}\right)$, indicating that they do not contribute to the rate-limiting step. The $\mathrm{E}_{\mathrm{B}} \bullet \mathrm{S}$ complex is partially active, but further arrangements in the active site lead to further improvements in reactivity. These rearrangements occur within a time scale similar to that of $k_{\text {cat }}$, suggesting that they may contribute at least in part to rate limitation. The conformational changes that take place in the active site can be described as an induced fit triggered by substrate and also, as the metal-ion replacement studies indicated, by the metal-ion cofactors. The H-bond network that links the two metal ions to the substrate binding pocket plays a pivotal role in mediating these structural changes and thus in fine-tuning the mechanism of action employed by GpdQ. The flexible coordination of Asn80 plays an important part in this mechanism. In this respect, GpdQ resembles another metalloenzyme, the mononuclear nonheme iron enzyme lipoxygenase from soybean (sLO). ${ }^{41}$ In sLO it was shown using site-directed mutants that the extent of coordination flexibility directly correlates with reactivity; the greater the flexibility, the greater the catalytic activity of the enzyme. It is believed that in lipoxygenase the flexible coordination allows for an optimal positioning of the substrate in the active site. The same is likely to be the case for GpdQ. Furthermore, the catalytic mechanism of GpdQ may also be related to other binuclear metallohydrolases, such as methionine aminopeptidase (MetAP) $)^{2,26,42,43}$ and metallo- $\beta$-lactamases (MBLs). ${ }^{5,44,45}$ However, MetAP is flexible in that it can operate as either a mononuclear or binuclear hydrolase, with each form having a distinct reaction mechanism..$^{2,26,42,43}$ Similarly, it

(41) Schenk, G.; Neidig, M. L.; Zhou, J.; Holman, T. R.; Solomon, E. I. Biochemistry 2003, 42, 7294-7302.

(42) Cosper, N. J.; D'souza, V. M.; Scott, R. A.; Holz, R. C. Biochemistry 2001, 40, 13302-13309.

(43) D'Souza, V. M.; Bennett, B.; Copik, A. J.; Holz, R. C. Biochemistry 2000, 39, 3817-3826.

(44) Cricco, J. A.; Orellano, E. G.; Rasia, R. M.; Ceccarelli, E. A.; Vila, A. J. Coord. Chem. Rev. 1999, 192, 519-535.

(45) Heinz, U.; Adolph, H. W. Cell. Mol. Life Sci. 2004, 61, 2827-2839. appears that some MBLs can operate as mononuclear enzymes, while others require two metal ions. ${ }^{5,44,45}$ In contrast, the present study supports a mechanistic model for GpdQ whereby the mononuclear form is inactive and a substrate- and metal-ioninduced fit leads to the formation of a catalytically active binuclear center, providing an intricate regulatory mechanism for enzyme activity ("on-off switch").

GpdQ is a very stable enzyme that has a flexible active site and displays very broad substrate specificity, hydrolyzing a large number of phosphate esters over a large $\mathrm{pH}$ range. Furthermore, both the reactivity and the reaction mechanism can be modulated by changing metal ions and specific amino acids. Together with the ease with which this enzyme can be recombinantly expressed and purified in large amounts, these properties and our increased understanding of their tuneability make GpdQ a promising target for the development of a bioremediator. Efforts to this extent are currently in progress.

Acknowledgment. This work was funded by the Australian Research Council (DP0986613). J.A.L. wishes to acknowledge the National Science Foundation for financial support through an NSF/ RUI grant CHE-0554083 and an instrument grant NSF/MRI CHE0820965. The authors express their gratitude toward Prof. Sunhee Choi for critically assessing the present study.

Supporting Information Available: Chemical structure of substrates $p$ NPP, Et $p$ NPP, and $b p$ NPP (Figure S1); determination of metal binding affinity of $\mathrm{M}(\mathrm{II})$ by kinetic assay $(\mathrm{M}=$ $\mathrm{Co}, \mathrm{Cd}, \mathrm{Mn}$ ) (Figure S2); reaction progress curves (Figure S3) and the effect of [S] on $k_{\mathrm{obs}(\mathrm{i})}$ (Figure $\mathrm{S} 4$ ) for the reaction of $p$ NPP with GpdQ; example of absorbance change over time for the reaction of $p$ NPP with GpdQ (Figure S5); reaction progress curves for N80A-GpdQ (Figure S6) and N80D-GpdQ (Figure S7). This material is available free of charge via the Internet at http://pubs.acs.org.

JA903534F 